\title{
A formal model of the human psyche life-supporting functions dialectic logic control
}

\author{
Victoria Kondratenko \\ V.M.Glushkov Institute of Cybernetics of NAS of Ukraine \\ Glushkov Avenue 40, Kyiv, Ukraine, 03187 \\ science.and.life@gmail.com, orcid.org/0000-0003-1577-6701 \\ Received 19.10.2019, accepted after revision 19.11.2019 \\ https://doi.org/10.32347/uwt2020.10.1201
}

\begin{abstract}
A lot of research in the field of artificial intelligence cannot be completed, or carried out at all, due to the lack of at the moment a correct theory of the human brain functioning associated with its intellectual activity, at least at a conceptual level. So far, there are no comprehensive proposals by researchers on what principles should be based on models of elementary and structured meanings processed by the brain in the course of human life, not to mention formal languages and their grammars, or, especially, formal theories designed for these purposes. The purpose of this article is to fill the gap in scientific knowledge about the human brain. Academician P.K. Anokhin in 1984 proposed the concept of a model for organizing and regulating a behavioral act, in which there is a place for all basic processes and conditions. It was called the functional system model. With such a model, it becomes possible in the same vein, using axiomatic statements, to create a logical-dialectical model of the functioning process at the physiological level of any of the higher mental functions. The dialectical logic of controlling any human body functional systems follows from the conceptual knowledge of the vital functions of these functional systems, obtained exclusively by natural experimenting. Therefore, the conceptual knowledge of the vital functions of each studied functional system of a person should precede the description of the logic essence of its control. The human psyche is one
\end{abstract}

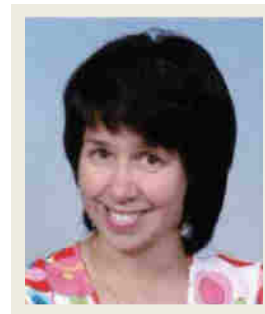

Victoria Kondratenko

Researcher of the Methods and technological construction tools of intellectual program systems Department

PhD, Ass. Prof.

of the most important functional systems of the human body. The article presents the fundamental concepts of the vital functions of this system, which allow revealing the essence of the dialectical logic of life-supporting functions control and a formal model of the dialectic logic of the human psyche functional system control.

Keywords: axiomatic modeling, artificial intelligence, mathematical logic, thinking, formalization.

\section{INTRODUCTION}

Relevance of the topic. The existence of a living matter, including complexly organized animals having nervous system (COAHNS) $[1,2,3,4]$, in a state of continuous and perpetual motion, caused not only the appearance of the psyche in the matter of these COAHNS, but also the possibility of creating various mental images based on this matter.

Mental images are used as reflections in the minds of an interacting pair of COAHNS individuals. 
The psyche is defined as the feature of highly organized matter of a particular subject to reflect the objective reality of the universe and, based on the mental image of this reality formed at the same time, to carry out not only operational, but also current and long-term management of the activity of this subject and its behavior. Reflection fixes in the memory of its consciousness the mental image formed by it (reflection) of the environmental impacts on it, which certainly agrees (image) with the worldview of the reflecting subject. The form of reflection depends on the form of existence of matter. In nature, there are three main forms of reflection. The lower life organization level corresponds to the physical form of reflection, characteristic of the interaction of inanimate nature objects.

Physiological form of reflection corresponds to the living matter.

The highest level of reflection in living matter takes the form of the most complex and perfect reflection - mental reflection.

The consciousness of a particular person integrates the diverse phenomena of human reality, transforming them into a truly holistic way of life of this person.

Consciousness is an integrated complex (system!) of higher mental functions (HMF) $[4,5,6,7]$, in which there are no fundamental and secondary functions. This is a set of 40-60 pcs equally important functions, implementing the highest level of the human psyche. Psychology professionals attribute them to artificial, instrumental, arbitrarily functions, controlled by a person, that have a social formation. But professionals in the area of neurophysiology, neuropsychology and biochemistry argue that HMF are implemented:

- Either on the genetic foundation of the neural networks fragments stereotypical architecture specifically designed for these purposes.

- Or, the human brain has a genetic neural structure loaded with the functions of a Universal Biological Architect, capable, in the space of its own population of neural stem cells by differentiating these cells, to create arbitrary neural network architectures designed to implement each of the HMFs.
The last two statements have yet to be clarified by natural scientists in the near future.

The vital activity of consciousness and HMF ceases with the death of a person.

For newborns, the process of HMF formation and consciousness begins from the moment they are born.

The approximate HMF list is as follows:

- reflection

- physical reflection

- physiological reflection,

- mental reflection,

- perception,

- presentation

- arbitrary attention,

- arbitrary memory,

- rational activity (extrapolation reflex),

- speech,

- writing

- logical thinking,

- imagination

- consciousness

- nine gnostic functions,

- twenty to forty intellectual functions.

It should be noted that the given approximate HMF list of is very far from perfect, due to the fact that so far psychologists, specialists in normal physiology, neurophysiologists, neuropsychologists, biochemists and cognitive specialists have no consensus and, moreover, a consensus:

- on the leading role of one of the HMF;

- on the classification of these functions and the algorithm of their interactions;

- about the tasks solved by each of them;

- about physiological processes that realize them;

- on the cerebral globe of the brain and spinal cord, fragments of which realize the function of the substrates of each of the HMF;

- on the unity of the mental, material and information functions in each of the substrates of living matter.

We will consider this phenomenon temporary, and that very soon it will be qualified by natural scientists. In the meantime, all professionals mentioned in the context attribute the leading role to consciousness, in spite of the HMF of logical thinking, not being embar- 
rassed by the fact that consciousness combines dozens of HMF.

If, yet, adhere to the rules of the protocol of agreements already reached in the field of reflection of knowledge about living matter in textbooks for biological and medical universities, then logical thinking, both of a mentor and a student, suggests the need to recognize the leading role of the HMF rational activity of a person. Although if only because it has, by universal admission of natural scientists, a genetic beginning and was first discovered experimentally as a sign of a psychic beginning in a person.

The discussions activity on the topics mentioned above has not subsided for at least the last three decades, but no noticeable progress in cognition of the human psyche has been observed.

The purpose of the article is to focus the attention of natural biologists on the lack of necessary knowledge in the field of dialectic logic of controlling the functional system of the human psyche, which, due to their fundamental nature, inhibits the knowledge of the neurophysiological processes secrets that realize his (person's) mental life. In particular, the knowledge formalization process in the field of theoretical medicine concerning the life of the functional system of the human psyche suffers to the maximum extent. It is these specialists who, like no one better, can see what knowledge and in what way can be obtained in a minimum amount of time. The article is devoted to the coverage of these problems.

The dialectical logic of controlling any functional systems of the human body follows from the conceptual knowledge of the vital functions of these functional systems, obtained exclusively through field experimentation. Therefore, the conceptual knowledge of the vital functions of each studied functional system of a person should precede the description of the essence of the management logic.

The problem formulation. The human psyche is one of the most important functional systems of the body, therefore, we will present the fundamental concepts of the vital activity of this system, which will allow us to identify the essence of the dialectical managing of lifesupporting functions logic [8-11].

\section{Human psyche life concepts}

Concept No 1. The psyche essence and the HMF role in human life.

The psyche (mental (from Greek)) is a genetically determined property of highly organized matter of the human body, consisting in its (matter) ability to reflect (subjectively reproduce!) using its own sensory organs and to fix a mental image in the memory of its nervous system (scene + scenario)), interacting with it the objective reality of the environment. The adjective "mental" focuses on the fact that the image (scene + script) is formed in the perception environment, due to the complex of knowledge about this environment, called the worldview of the reflector.

The mental images accumulated by the subject about the life of the universe are used throughout his life, both for the operational and for the current and long-term management of his own life and his behavior.

The HMF control algorithm as a part of a functional system called the psyche is not yet known to natural scientists. And according to my ideas, no one has yet studied this topic in the international scientific community, since publications on it have not yet been encountered in international scientific journals.

As well as the list of HMF specific functional capabilities of human rational activity is thoroughly known to no one. Although for the leading role among all HMF, it is objectively the number one contender.

It remains nothing but hope that this publication will arouse interest in the announced research topics and the results will not be long in coming.

In the meantime, in addition to the HMF presented above, it is possible to reveal generalized names of Gnostic and intellectual functions.

Gnostic (underlying) functions of natural phenomena cognition:

- purpose of functioning;

- motivation for functioning; 
- morphology of a cognizable phenomenon;

- assessment of operation accuracy and reliability;

- identification of energy sources necessary for functioning;

- assessment of energy required for operation;

- physical forces that ensure the functioning process;

- types of movements of matter on which functioning is based;

- relation between physical variables that are functionally fully characterizing the functioning of the phenomenon under study.

\section{Smart features}

Intelligence (from the Latin intellectus understanding, cognition) is the main form of human cognition of reality. In a broad sense, this is the totality of all individual cognitive mental functions: from sensation and perception to thinking and imagination; in a narrower sense, it is thinking. This definition of intelligence is accepted in modern national psychology.

The basic HMF list (higher mental functions) that make up the intellect is as follows:

- consciousness;

- perception;

- memory;

- thinking;

- speech;

- writing;

- score;

- arbitrary movements;

- understanding of relative movements;

- understanding of rhythms in movement and in sensory perceptions;

- imagination;

- recognition of familiar sensory images;

- recognition of familiar compositions (scenes) of sensory images;

- understanding the structure of sign systems (solving the problems of semiology);

- solving logical problems;

- solving problems of spatial geometric constructions;

- solving game problems with the antagonistic warring goals;
- reproduction of graphic or pictorial copies of the observed phenomena;

- fine art, literary and musical creativity;

- scientific creativity;

- substantial evidence of predictive logical statements;

- control and management of the autonomic nervous system.

However, you must admit that without the HMF control algorithm, which is part of the human body psyche functional system (HBPFS), known only through HBPFS fullscale experimentation, it is fundamentally impossible to understand the control logic of it (the psyche) by life-supporting functions.

Therefore, based on the knowledge of the human psyche set forth in this concept, we formulate the following axiom:

Axiom No.1. The human psyche as a whole, with all its HMF, from the point of view of a natural scientist-neurophysiologist, is a script generator, reflected in the format of the second signal system symbols, all admissible states of its nervous system, and, at the same time, the director of the implementation of these scenarios, guided by: environmental influences, interactions with the environment and a mental imitation of the "self" interaction with its own psyche.

This generator and director provides the solution to the following human life support tasks:

- active, but at the same time subjective reflection by this real universe individual;

- adaptive regulation of the one's own body state in accordance with the current environmental influences and current interactions;

- adaptive operational behavior management and reactions in accordance with the current environmental impacts and current interactions;

- the possibility of a mental imitation of the "self" interaction with his own psyche.

Guided by the ultimate goal of knowing the human psyche, and knowing the real state of this knowledge from the point of view of the psyche integrity as a functional system of the human body, I believe that we stay without answers to two questions: 
- constructing (on the basis of the facts of full-scale experimentation with the functional system of the psyche) a HMF network management model of this system when solving the tasks just listed for the life support of the human body;

- on the basis of the HMF network model of management to identify the dialectic logic of its management (psyche) of lifesupporting functions;

the psyche cognition cannot be considered successful. Such a level of cognition cannot be called failure otherwise. And, of course, there is a need for its urgent completion, but according to the program proposed in the article. Such actions determine the purpose of publishing the article. However, we must not forget that the psyche functional system, of course, being the most important in the environment of many other functional systems of the human body, continuously interacts with these other systems, and the quality of its functioning directly depends on this interaction. This will be discussed in the following concepts about some related HMF functional systems and the features [12, 13-18].

Concept No 2. The HMF leading role of rational activity in the sphere of the functional system action of the human psyche can be recognized only after exhaustive scientific knowledge of the biological tools that implement it. Including its functional capabilities, an algorithm for implementing these capabilities, plus the architecture of fragments of a neural network in the brain globe of the brain and spinal cord, which implement the full HMF functionality of rational activity. We identify this concept as Axiom No.2.

Concept No.3. Human evolution of the second signal system (speech, writing, reading) in addition to the first signal system (sensory), led to the generation in the body of the psyche as a separate body functional system, the material carrier (substrate) of which is the central nervous system (CNS). The psyche provides:

- interpretation of the universe phenomena reflected by it in human memory, in the format of functional information about this phenome- non, but not related to the substrate and its properties;

- interpretation of any functionality of the human body in the format of a controlled information process of movement and processing of the following types of information: 1) stored in its memory; 2) outgoing from the external environment (sensory); 3) coming from the analytical and associative centers of the cerebral cortex and its centers of motivation, will and emotions; 4) as well as coming from all feedback sources.

We identify this concept as Axiom No 3.

Concept No 4. The basis of the human body vital functions are the unconditioned reflex reactions of the organism to disturbances in the living environment, or disturbances in the internal environment of the organism. We identify this concept as Axiom No 4.

Concept No 5. The conditioned human body reflex activity is based on unconditioned reflex activity. We identify this concept as Axiom No 5.

Concept No 6. The human cerebral cortex activity has the most developed ability to analyze and synthesize signals from the surrounding and internal environment of the body. The analytical activity of the cortex is: a subtle distinction (differentiation) in the nature and intensity of the action of many stimuli acting on the body and reaching in the form of nerve impulses to the cerebral cortex. Due to internal inhibition in the cortex, differentiation of stimuli by the degree of their biological significance is carried out. This differentiation is analogous to the logical summation operation performed by the processor of the analytical zone.

The synthetic cortex activity is manifested in the binding, association of excitations that arise in different zones of the cortex, which forms complex forms of human behavior. This binding is an analogue of the logical multiplication operation, which is performed by the processor of the associative zone in the cerebral cortex. The neurons of the associative zone are not connected with the sensory organs or muscles, they communicate between different areas of the cortex, integrating, com- 
bining all the impulses entering the cortex into integral acts of learning (reading, speech, writing), logical thinking, memory and providing the possibility of appropriate behavior reactions. We identify this concept as Axiom No.6.

Concept No 7. All anatomical components of the human body, external and internal, are permeated with various types of receptors, which are designed to control and regulate the permissible states of these components. We identify this concept as Axiom No 7.

Concept No 8. Conscious human activity is realized solely by the functional system of the human psyche, which includes the central and peripheral nervous system of a person. In this case, it is carried out:

- coding of processed information (engrams);

- associative information retrieval (engram);

- addressing of engrams during writing and reading;

- synchronization of writing and reading engrams;

- transformation of complex multimodal perceptions formats (unconscious memory) into conscious information formats (glosses, meanings);

- logical analysis of engrams performed in the analytical zone of the cortex;

- logical synthesis of engrams performed in the associative zone of the cortex.

We identify this concept as Axiom No 8.

Concept No 9. HMF of consciousness implements the list of functional capabilities identified in the process of exclusively fullscale experimentation [19-22]:

Model (in the form of sensory, speech, written, graphic, and engineering-graphic images) of subjective reflection in a person's memory of his interaction with environmental realities, which are the components of the universe.

Model subjective reflection in human memory of the accumulative knowledge results of the universe new fragments.

Providing the generating based on the accumulated knowledge of behavioral functions that allow a person to:

adequately navigate in space and time of the universe; adequately assess the personal status in the environment;

adequately be guided by the laws of life in the environment;

ensure in time the systematic and integrity of the laws of life;

make the work socially useful, associated with the production of goods necessary for the life of society;

carry out an internal mental dialogue, which is the basis of the fruitful thinking of this person.

We identify this concept as Axiom No 9.

Axiom No 10. The spiritual life of a person is mediated by the dialectical logic of controlling his psyche functional system.

A formal model of the human psyche lifesupporting functions dialectic logic control.

If axioms A1 - A9 and their causal relations between themselves and axiom A10, which reflects one of the psyche modeling goals, are described in the formal language of first-order predicate logic, then we get the desired model of the dialectic logic of controlling the psyche functional system.

We proceed to the process of describing the first-order predicate logic the dialectic logic of controlling the functional system of the psyche, reflected in the context of the article using the axiomatic text A1 - A10.

Replace the axiom $\mathrm{A}_{\mathrm{z}}$ with a logical function called the predicate:

$\mathrm{A} 1 \equiv \mathrm{p} 1(\mathrm{X})$, in which the predicate symbol $\mathrm{p} 1$ is loaded with the meaning of the axiom $\mathrm{A} 1$, and the object variable $\mathrm{X}$ identifies the person in question.

$\mathrm{A} 10 \equiv \mathrm{p} 10(\mathrm{X})$, in which the predicate symbol p10 is loaded with the meaning of the axiom A10, and the objective variable $\mathrm{X}$ identifies the person concerning the psyche.

Based on the axioms A1 - A10, one can formulate the following target theorem:

The logical product of the axiom premises A1 - A9 provides an adequate spiritual life of a person.

This theorem formally looks like this: $\mathrm{A} 1 \Lambda \mathrm{A} 2 \Lambda \ldots \Lambda \mathrm{A} 9=\mathrm{A} 10$.

What is reflected in the predicate form: 


$$
\begin{array}{r}
(\forall \mathrm{X})((\mathrm{p} 1(\mathrm{X}) \Lambda \mathrm{p} 2(\mathrm{X}) \Lambda \ldots \Lambda \mathrm{p} 9(\mathrm{X}))= \\
\mathrm{p} 10(\mathrm{X}))
\end{array}
$$

Understanding the physiological meaning of logical operations used to reflect physiological phenomena, for example, in formula (1), is achieved by combining this formula with the help of an implication operation with one of its interpretations [6-8], but obtained by natural experimentation, always with the knowledge of the person for whom the formula is applied (1).

As a result, the formal model of the dialectic logic of controlling the psyche functional system will have the following form:

$$
\begin{array}{r}
((\forall \mathrm{X})((\mathrm{p} 1(\mathrm{X}) \Lambda \mathrm{p} 2(\mathrm{X}) \Lambda \ldots \Lambda \mathrm{p} 9(\mathrm{X}))=> \\
\mathrm{p} 10(\mathrm{X})))=>((\exists \mathrm{X})((\mathrm{p} 1(\mathrm{X}) \Lambda \mathrm{p} 2(\mathrm{X}) \Lambda \ldots \Lambda \\
\mathrm{p} 9(\mathrm{X}))=>\mathrm{p} 10(\mathrm{X})))
\end{array}
$$

Transformation of the model of the theorem to the canonical form

If in the formula (2) the expression:

$$
((\mathrm{p} 1(\mathrm{X}) \Lambda \mathrm{p} 2(\mathrm{X}) \Lambda \ldots \Lambda \mathrm{p} 9(\mathrm{X})) \equiv \mathrm{F} 1(\mathrm{X})
$$

will be replaced by the formula $\mathrm{F} 1(\mathrm{X})$, then the formula (2) will take the following form:

$$
\begin{aligned}
(\forall X)(F 1(X)= & p 10(X))=> \\
& (\exists X)(F 1(X)=>p 10(X))
\end{aligned}
$$

In the theory of theorems automatic proof, in order to reduce logical formulas to a canonical format containing only axioms and three logical operations (conjunctions, disjunctions, and negations), 27 formal rules of equivalent transformations of first-order predicate logic formulas are defined and proved.

Two of them look like this:

$$
\begin{aligned}
& (\mathrm{F} 1(\mathrm{X})=>\mathrm{F} 2(\mathrm{X})) \equiv(\mathrm{IF} 1(\mathrm{X}) \mathrm{V} F 2(\mathrm{X})) \\
& (\mathrm{F} 1(\mathrm{X})=>\mathrm{F} 2(\mathrm{X})) \equiv\left(\mathrm{F} 1(\mathrm{X}) \Lambda^{\prime} \mathrm{IF} 2(\mathrm{X})\right)
\end{aligned}
$$

One of the rules sets

$$
\text { 'I } \exists \equiv \forall
$$

One of the rules prescribes to free a formula from all quantifiers of generality if there are no other quantifiers in the formula.

If you use these four last rules, then the formula (3) in the first step will take the following form:

$$
\begin{aligned}
&(\forall X)(\operatorname{IFl}(X) \vee \mathrm{p} 10(\mathrm{X}))=>(\exists X) \\
&(\mathrm{IFl}(\mathrm{X}) \mathrm{V} \mathrm{p10}(\mathrm{X})) .
\end{aligned}
$$

And at the next step (4) it is converted to:

$$
(\mathrm{IF} 1(\mathrm{X}) \mathrm{Vp} 10(\mathrm{X})) \Lambda^{\prime} \mathrm{I}(\mathrm{IF} 1(\mathrm{X}) \mathrm{Vp} 10(\mathrm{X}))(5)
$$

\section{Proof of the theorem}

Formula (5) is a conjunction of only two counter-components.

This indicates its inconsistency, but also testifies to the truth of the theorem as a whole, since the methodology for the automatic proof of theorems is based on the conclusion that the formula of the theorem as a whole is inconsistent.

Therefore, the theorem is successfully proved.

\section{CONCLUSION}

The created model can be transformed, depending on the set goal of the human psyche cognition, it can be considered as an example of modeling and a demonstration of the modeling methodology used. As researchers gain new knowledge in various fields of science about the psyche functioning, the model can be supplemented with concepts, axioms, refined, etc. It is important that the resulting model preserves the knowledge heritability of the human psyche and, in the case of formal proofs, the truth of the statement of the theorem will be proved analytically and mathematically accurately.

\section{REFERENCES}

1. Kondratenko V.A., 2015. Paradoxes of science of the twentieth century. The twenty first century - dialectic logic against mysticism, Kyiv, Scientific publication Zadruga, 
200 (in Russian).

2. Kondratenko V.A., 2014. A living matter in an image of formal models (From physiological heredity to intelligence with its assets). The collection of articles of the author, Kyiv, Scientific publication of LLC, Yunik Print, 186 (in Russian).

3. Kondratenko V.A., 2010. Creation of a uniform stereotype of a logical design of thinking for the substantial and formal proof of theorems. Kyiv Scientific publication of Alephof, 267 (in Russian).

4. Kondratenko V.A., 2017. Artificial intelligence. A plan and realities of the current time against the background of natural intelligence of the person. Kyiv, Scientific publication Zadruga, 84 (in Russian).

5. Lyalkina G.B., 2012. Mathematical foundations of decision theory. Ed. V.A. Trefilova. Guidance. Perm, Perm Publishing House. Polytechnic University, 118 (in Russian).

6. Anokhin P.K., 1998. Chosen works. Cybernetics of functional systems. Moscow, Medicine, 400 (in Russian).

7. Agadzhanyan N.A. Tel L.Z., Tsirkin V.I., Chesnokova S.A., 2003. Human physiology. (The textbook for medical higher education institutions), under the editorship of the academician of the Russian Academy of Medical Science Agadzhanyan and professor N.A. Tsirkin, the Medical book, N. Novgorod, NGMA Publishing house, 408 (in Russian).

8. Kondratenko V.A., 2016. Dialectic logic of management of the autonomic nervous system of the person. Computer mathematic, No.1, 125-133 (in Russian).

9. Kondratenko V.A., 2016. Mathematical models of physiological processes of metabolism, reflex and intellectual activity head vegetable pulp of the person. Kyiv, Scientific publication Zadruga, 128 (in Russian).

10. Kondratenko V.A., 2018. Formal logical-dialectical models of higher mental functions of a person, as the basis of creative scientific thinking. $X$ International Symposium "Actual Problems of Biophysical Medicine", Kyiv Material of the International Symposium 16-18 May 2018, 30, 30 (in Russian).

11. Chen Ch., Li R., 1983. Symbolic Log- ic and Mechanical Theorem Proving. Chapter 5. Method of resolutions, Mathematical logic and automatic proof of theorem. Academic Press, Moscow, Science, 358 (in Russian).

12. Guts A.K. Chapter, 2003. Method of resolutions, Mathematical logic and theory of algorithms. Omsk, Heritage. Dialogue Siberia, 108 (in Russian).

13. Nilsson N.J., 1982. Principles of artificial intelligence. Springer-Verlag Berlin Heidelberg, 476.

14. Mendelssohn E., 1984. Introduction to mathematical logic, Moscow, Nauka, 320 (in Russian).

15. Russell S., Norvig P., 2009. Artificial intelligence: a modern approach, 3rd ed. Prentice Hall, 1152.

16. Turing A., 1950. Computing Machinery and Intelligence. Mind, Vol.59, No.236, 433-460.

17. Vladislav Bogdanov, 2017. Impact of a hard cylinder with flat surface on the elastic layer. Underwater Technologies, Vol.05, 8-15.

18. Nikolay Zhuk, Myron Nazarian, Yury Stelmakhov, 2015. Great Silk Road: modern problems of reconstruction. Underwater Technologies, Vol.01, 59-64 (in Russian).

19. Petro Kulikov, Mykhailo Sukach, 2016. Program of development of minerals of the World ocean, Underwater Technologies, Vol.03, 3-14 (in Russian).

20. Artobolevsky S.S. (ed.), Sintserov L.M., 2010. Compression of the socioeconomic space: new in the theory of regional development and the practice of its state regulation. Moscow, Eslan, 6 (in Russian).

\section{Формальная модель диалектической логики управления жизнеобеспечивающими функ- циями психики человека}

\section{Виктория Кондратенко}

Аннотация. Множество исследований в области искусственного интеллекта не могут быть завершены, или проведены вообще, из-за отсутствия на текущий момент корректной теории функционирования человеческого мозга, связанного с его интеллектуальной деятельностью, хотя бы на концептуальном уровне. Нет 
пока комплексных предложений исследователей, на каких принципах должны основываться модели элементарных и структурированных смыслов, обрабатываемых мозгом в процессе жизнедеятельности человека, не говоря уже о формальных языках и их грамматиках, или, тем более, о формальных теориях, предназначенных для этих целей. Цель статьи заключается в восполнении отмеченного пробела в научных знаниях о человеческом мозге. Академик П.К. Анохин в 1984 году предложил концепцию модели организации и регулирования поведенческого акта, в которой есть место для всех основных процессов и состояний. Она получила название модели функциональной системы. При наличии такой модели появляется возможность в том же ключе, с помощью аксиоматических утверждений, создать логико-диалектическую модель процесса функционирования на физиологическом уровне любой из высших психических функций. Диалектическая логика управления любыми функциональными системами организма человека вытекает из концептуальных знаний о жизнедеятельности этих функциональных систем, добытых исключительно путём натурного экспериментирования с ними. Поэтому концептуальные знания о жизнедеятельности каждой исследуемой функциональной системы человека должны предшествовать описанию сущности логики управления ею. Психика человека является одной из важнейших функциональных систем организма человека. В статье представлены основополагающие концепты жизнедеятельности этой системы, которые позволяют выявить сущность диалектической логики управления её жизнеобеспечивающими функциями, и формальная модель диалектической логики управления функциональной системой психики человека.

Ключевые слова: аксиоматическое моделирование, искусственный интеллект, математическая логика, мышление, формализация. 